\title{
COMPARISON BETWEEN THE OUTCOME OF TUNICA VAGINALIS BLANKET WRAP AND NON-WRAP PROCEDURES IN URETHROPLASTY.
}

\author{
MOHAMMAD MINHAJUDDIN SAJID (SAJID M M) ${ }^{1}$, MD. SHAHID KARIM (KARIM M S) ${ }^{2}$
}

\begin{abstract}
Background: Hypospadias is a developmental anomaly characterized by a urethral meatus that opens onto the ventral surface of the penis, proximal to the end of glans.

Fistulas are the most common complication following hypospadias repairs. This study was carried out to see that application of vascularized Tunica Vaginalis Blanket Wrap (TVBW) in urethroplasty reduces fistula rate in hypospadias repair.
\end{abstract}

Objectives: To study the efficacy of Tunica vaginalis blanket wrap to prevent urethrocutaneous (UC) fistula in urethroplasty for hypospadias repair.

Methods:

Study Design : Prospective comparative study

Place of Study :Department of Paediatric surgery, Dhaka Shishu Hospital (DSH), Dhaka.

Period of Study :April, 2003 to October, 2004 for a total period of 19 months.

The study of population : Twenty (20) admitted patients of hypospadias were selected. Patients were grouped into group A and group B on the basis of lottery method. Group A

included 10 cases, who were subjected to repair of hypospadias with the application TVBW. Group B included 10 cases, who were subjected to repair of hypospadias without TVBW.

1. Dr. Mohammad Minhajuddin Sajid, Assistant Professor, Department of Paediatric Surgery, Chittagong Medical College \& Hospital, Chittagong, Bangladesh.

2. Professor Md. Shahid Karim, Prof. \& chief consultant, Department of Paediatric Surgery, Apollo Hospital, Bashundhara, Dhaka, Bangladesh.

Correspondence to: Dr. Mohammad Minhajuddin Sajid, Assistant professor, Department of Paediatric Surgery, Ward-11B, Chittagong Medical College \& Hospital, Chittagong, Bangladesh. Mobile: +8801911811421, E-mail: minhajsajid@ yahoo.com, minhajusajid@gmail.com
Statistical Analysis : Chi-square test $\left(X^{2}\right.$ test) were applied. $p$ value $<0.01$ was taken as significant.

Ethical aspect : Research protocol was accepted by DSH. Written consent were taken from parents.

Result: Occurrence of post operated UC fistula found significantly higher in non TVBW.

Discussion: In our patients for group A (study group), TVBW was used in urethroplasty while urethroplasty for group $B$ (control group) was carried out without TVBW. UC fistula was present in 1 patient $(10 \%)$ in group A post operatively and in 5 patients $(50 \%)$ in group B postoperatively and subsequently 2 more patients developed fistula during follow up period. In control group 7 patient $(\mathbf{7 0} \%)$ developed UC fistula out of 10 patients $(n=10)$ despite of using periurethral flap of tissue as second layer over the neourethra. In our study, the rate of development of UC fistula is much less (only $10 \%$ ) in study group. So the result is significant as evidenced by $p$ value which is less than $<0.01$.This study demonstrates that use of tunica vaginalis as a blanket wrap as second layer over the neourethra reduces the rate of development of UC fistula.

Conclusion: TVBW is recommended for urethroplasty to decrease the postoperative UC fistula.

Keywords: Hypospadias, Urethroplasty, Tunica vaginalis blanket wrap, Fistula

\section{Introduction}

Hypospadias is a developmental anomaly characterized by a urethral meatus that opens onto the ventral surface of the penis, proximal to the end of the glans. The meatus may be located anywhere along the shaft of the penis, from the glans to the scrotum, or even in the perineum ${ }^{1}$.It is one of the commonest congenital abnormalities of the male genitalia occurring in approximately 0.8-8.2 per 1000 live male births or 1 in every 300 male child ${ }^{2}$. Anterior 
hypospadias are glanular, coronal and anterior penile. In the middle hypospadias falls mid penile. Posterior hypospadias are posterior penile, penoscrotal, scrotal and perineal.Classically three abnormalities are found in the hypospadiac penis (1) an ectopic opening of the urethral meatus (2) a ventral curvature of the penis (Chordee) and (3) a hooded foreskin on the dorsum of the penis and a lack of skin on the ventrum due to a V-shaped defect referred to as urethral delta. The Chordee of the hooded foreskin are not constant, and a hypospadiac meatus may be found under a normally formed prepuce; Chordee may be isolated without an ectopic urethral opening, but is often associated with a hyperplasia of the corpus spongiosum ${ }^{3}$. More than 300 types of urethroplasties have been described in the literature and new techniques and modifications continually appear which confirms that it is a difficult surgery with many complication and frequently inadequate cosmetic and functional results. Because of the wide variation in the anatomic presentation of Hypospadias, no single method of urethroplasty is applicable is applicable to all cases. Despite extensive advances in surgical technique, fine suture materials, delicate instruments, proper tissue handling, advances in anesthesia Hypospadias patients face a lot of postoperative complication. The type and incidence of complication vary with the particular form of hypospadias and its repair. Fistulas are the most common complication following hypospadias repairs. Many efforts to prevent the formation of urethrocutanenous fistulas have been developed and tried with various degrees of success. Among these efforts have been avoidance of overlapping suture lines, two stage repairs rotating skin flaps, denuding epithelium and overlapping the denuded subcutaneous tissue using as much vascularized flap as possible such as using preputial inner vascular flap etc. All these have been used in out hospital but with no good results. In 1985, a random pedicle flap of tunica vaginalis was developed and used as vascularized tissue in hopes of covering the new urethra like a blanket to prevent the formation of UC fistulas with the success rate of $91 \%{ }^{4}$. The fistula rate for the meatoplasty and glanuloplasty (MAGPI) procedure varied from $0.5 \%$ to $10 \%$ whereas the fistula rate for flip-flap repairs varied from $2.2 \%$ to $35 \%$. Fistula rate varied from $4 \%$ to $33 \%$ for island pedicle tube repairs. Free grafts tube repairs encountered even higher fistula rates of $15 \%$ to $35 \%{ }^{5}$.T prevent $\mathrm{UC}$ fistulas long standing principles of hypospadias repair dictate that overlapping suture should be avoided and interposition of layers of tissue between the urethral suture line and the skin suture line is beneficial ${ }^{6}$. This prospective comparative study was conducted with the hypothesis that application of TVBW in urethroplasty reduces fistula rate in hypospadias repair. The aims and objectives of this study are to study the efficiency of TVBW in urethroplasty in hypospadias repair by observing the rate of development of fistula in urethroplasty and the cosmetic appearance of the penis and other complications.

\section{Materials and Methods:}

Study Design : Prospective comparative study

Place of Study : Department of Paediatric surgery, Dhaka Shishu Hospital (DSH), Dhaka.

Period of Study : April, 2003 to October, 2004 for a total period of 19 months.

The study of population : Twenty (20) admitted patients of distal, mid and proximal penile hypospadias in DSH were selected for this study. Patients, after the admission, who fulfilled the inclusion criteria of the study were included in the study. Necessary informations regarding the study and as per data sheet were taken from the attendants.

\section{Grouping of the patients :}

20 proposed patients were grouped into group $A$ and group B on the basis of lottery method. 10 tickets of Group A scripted lottery was allotted urethroplasty with TVBW. 10 ickets of Group B scripted lottery was allotted urethroplasty without TVBW. After picking up one lottery ticket by patient, it was discarded from the basket.

Group A : Included 10 cases, who were subjected to repair of hypospadias with the application of tunica vaginalis blanket wrap (TVBW).

Group B : Included 10 cases, who were subjected to repair of hypospadias without the application of TVBW.

\section{Criteria for Case Selection :}

A. Inclusion Criteria :

* Patients with anterior, middle and posterior variety hypospadias admitted in the department of pediatric surgery of DSH between $1^{\text {st }}$ April 2003 to $31^{\text {st }}$ October 2004 were included in the study group. 
* All cases were randomly distributed.

${ }^{*}$ Age up to 12 years.

B. Exclusion Criteria :

* Patients having glanular and coronal variety of hypospadias.

* Cases with the previous history of operation in the inguninoscrotal region for other reasons.

* The patient who did not give consent to the operative or randomly assigned procedure were excluded from the study.

Methods of data Collection : Every patient was thoroughly examined and diagnosis was confirmed by clinical examination and relevant investigations were done.

Operative Technique : All patients were operated upon under general anesthesia with caudal epidural block with bupivacaine.

a) Patients in group A were subjected to urethroplasty with the application of tunica vaginalis blanket wrap (TVBW).

b) Patients in group B were subjected to urethroplasty without the application of TVBW.

As already mentioned, Chordee, if any, is corrected and urethroplasty is performed. At the base of penis, where the penis has been degloved, two small retractors are placed. To procure the tunica vaginalis, the testis is pushed into view at the penoscrotal junction. The scrotal attachment to tunica vaginalis and testis are separated and the tunica vaginalis and testis are delivered to the wound. Dissection of the attachment along the spermatic cord is completed and tunica vaginalis is opened distally and dissection is carried out proximally towards superficial inguinal ring. A longitudinal incision is made along the lateral margin of the sleeve and dissection is completed.

Now the neourethra in place, the penis covered with the tunica vaginalis up to two thirds to three fourths of the circumference and to the tip of neourethra. Then after stitching it, the skin is closed.

\section{Postoperative care :}

- All patients were treated by antibiotics for a minimum period of 10 days.
- Postoperative analgesia was maintained with per rectal diclofenac suppositories, paracetamol syrup and injection pethidine intramuscularly in some cases and also by the

- Effect of caudal anesthesia. Average postoperative hospital stay was 10 days.

- Urinary diversion in the form of urethral feeding tube were kept in position for 10 days.

- Dressing was changed on $6^{\text {th }}$ postoperative day and details of healing patterns and other findings were registered.

Statistical Analysis : Data were processed \& analyzed with the help of a resource person. The data were collected in a preformed data sheet and were expressed in the text and

tables as mean $\pm S D$ (standard deviation). Comparison between the two groups was obtained by Chi-square test $\left(X^{2}\right.$ test $)$. $p$ value $<0.01$ was taken as significant.

Ethical aspect : Research protocol was accepted by DSH. After verbal counseling written consent were taken.

\section{Results:}

Types of Hypospadias :

In our study, 4 patients (40\%) in group $A$ and 4 patients $(40 \%)$ in group $B$ presented with distal penile variety. 1 patient $(10 \%)$ in group $A$ and 3 patients $(30 \%)$ in group $B$ represented with middle penile variant. 5 patients $(50 \%)$ in group $A$ and 3 patients $(30 \%)$ in group $B$ presented with proximal penile variant.

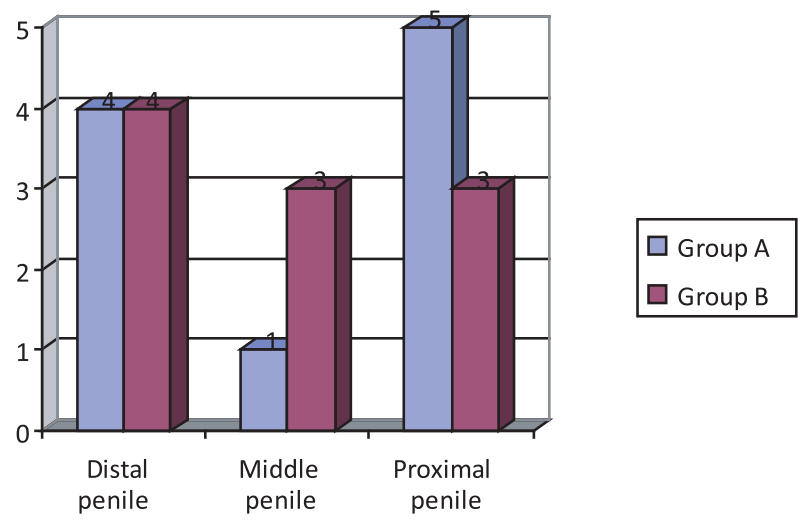

Fig.-1: Types of hypospadias according to the location of meatus 
Presence of Chordee and metal stenosis :

In our study $80 \%$ (8 patients) in group A and $80 \%$ (* patients) in group $B$ presented with Chordee in all variant of Hypospadias (anterior, middle and posterior). In the rest 4 of he posterior Hypospadias, Chordee was corrected previously in first staged operation. GRAPH

Metal stenosis was present in $20 \%$ (2 patients) in group A and in 50\% (5 Patients) in group B.

\section{Stages of repair and surgical procedure of} Hypospadias :

7 patients $(70 \%)$ in group $A$ and 8 patients $(80 \%)$ in group $B$ had single stage repair of hypospadias by Snodgrass method (Snodgrass 1994) while 3 patients $(30 \%)$ in group $A$ and 2 patients $(20 \%)$ in group B underwent staged repair of Hypospadias by KingsDuplay type tube ${ }^{7}$.

\section{Outcome of repair of Hypospadias :}

Post urethroplasty Complications in the study group and control group of patients

Posturethroplasty follow up, in this series, shows that postoperative fever occurred in 1 patient $(10 \%)$ in group B which remained up to 4 days. Postoperative infection developed in 1 patient $(10 \%)$ in group in group B which was found to be UTI with discharge of pus. The pus was sent for culture and sensitivity and was treated accordingly with antibiotics.

UC fistula was present in 1 patient $(10 \%)$ in group $A$ and in 5 patients $(50 \%)$ in group B post operatively.

Post discharge complication in the study group and the control group of patients :

Complications which developed after discharge in the follow up period is summarized in Table $X$ and Fig 12 urethrocutaneous fistula occurred in 1 patient $(10 \%)$ in group $A$ and in 7 patients $(70 \%)$ in group B. Fistula occurred in 5 patients of anterior penile variety of anterior Hypospadias, 2 patients of penoscrotal variety of posterior Hypospadias and 1 patient of middle penile variety of middle hypospadias. In group A meatal Stenosis occurred in 4 patients in $1^{\text {st }}$ follow up, which responded to dilatation in 2 patients in $2^{\text {nd }}$ follow up and till the end of $3^{\text {rd }}$ follow up 1 patient was continuing regular meatal dilatation. In group $B$, meatal Stenosis occurred in 4 patients in $1^{\text {st }}$ follow up which responded to dilatation in 3 patient in $2^{\text {nd }}$ follow up and till the end of $3^{\text {rd }}$ follow up 1 patient was continuing regular meatal dilatation. In study group $A$ urethral stricture occurred in 1 patient $(10 \%)$ in $2^{\text {nd }}$ follow up which was treated with regular urethral dilatation under general anesthesia.

Table I

Complications developed in post discharge follow up in the study group and the control group of patients

\begin{tabular}{|c|c|c|c|c|c|c|}
\hline \multirow[t]{3}{*}{ Complication } & \multicolumn{3}{|c|}{ Study group A $(n=10)$} & \multicolumn{3}{|c|}{ Control group B $(n=10)$} \\
\hline & No $\%$ & No $\%$ & No $\%$ & No $\%$ & No $\%$ & No $\%$ \\
\hline & $1^{\text {st }} \mathrm{FU}$ & $2^{\text {nd }} \mathrm{FU}$ & $3^{\text {rd }} \mathrm{FU}$ & $1^{\text {st }} \mathrm{FU}$ & $2^{\text {nd }} \mathrm{FU}$ & $3^{\text {rd }} \mathrm{FU}$ \\
\hline Urethrocutaneous fistula & $1(10 \%)$ & $1(10 \%)$ & $1(10 \%)$ & $7(70 \%)$ & $7(70 \%)$ & $7(70 \%)$ \\
\hline Meatal Stenosis & $4(40 \%)$ & $2(20 \%)$ & $1(10 \%)$ & $4(40 \%)$ & $3(30 \%)$ & $1(10 \%)$ \\
\hline Urethral Stricture & 0 & $1(10 \%)$ & 0 & 0 & 0 & 0 \\
\hline Persistent Chordee & 0 & 0 & 0 & 0 & 0 & 0 \\
\hline Shape of the glans & 0 & 0 & 0 & 0 & 0 & 0 \\
\hline Size of the testis & 0 & 0 & 0 & 0 & 0 & 0 \\
\hline
\end{tabular}


After applying a test of significance for the major complication of urethrocutaneous fistula by $\mathrm{Chi}$ square test, $p$ value was observed to be $<0.01$, which means that the surgical outcome of hypospadias surgery between study group (A) and control group $(B)$ is significantly different.

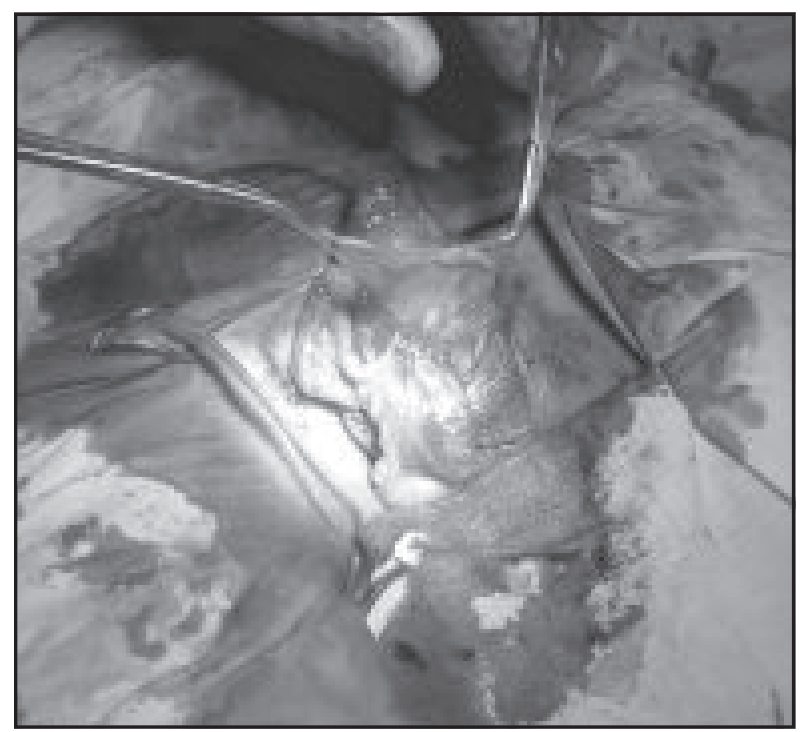

Fig.-2: Harvesting the TV flap prior to application over the neourethra.

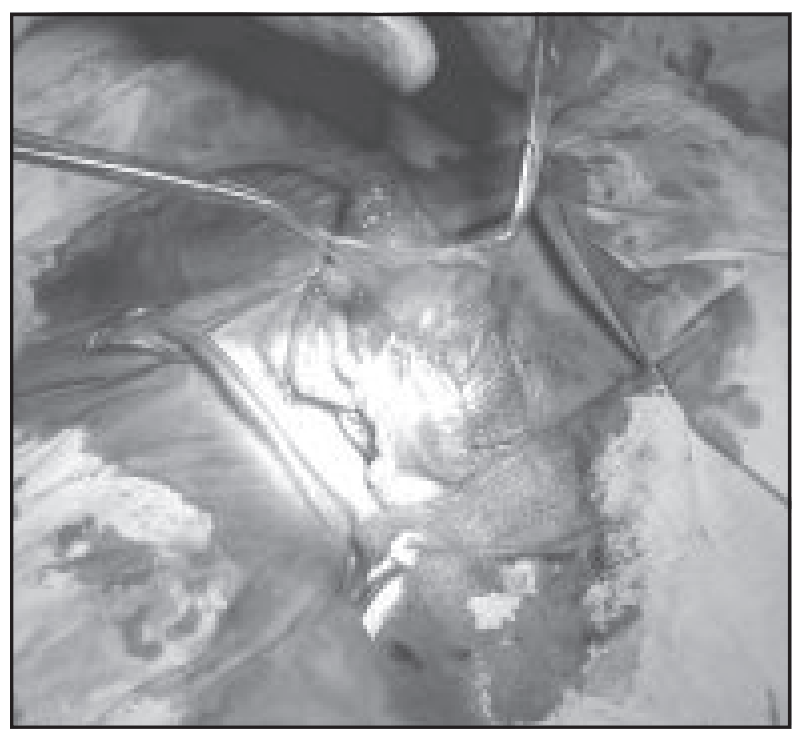

Fig.-3: TV flap wrapped over the neourethra and sutured.

\section{Discussion:}

In our study we included patients of age ranging from 1.5 years to 12 years. In the study group (group A), mean age of the patients was $4.72 \pm 2.85$ years and in the control group (Group B), mean age was $5.99 \pm 2.96$ years. 12 patients $(60 \%)$ Most patients presented to the hospital at their 1 to 5 years of age. Both the study group and control group are comparable in age.

Schultz and colleagues ${ }^{8}$ pointed out that an ideal time for hypospadias repair might be 6 to 18 months of age to minimize the emotional effect of this traumatic insult. Some believe that this timing does not appear to be appropriate for Bangladesh. The appropriate or optimum age of operation time is to be considered 2-3 or 3.5 years of age in order to obtain a sizeable phallus, avoiding inconvenience of absenteeism from school, counting the period of breast feeding and the mother recovering form pre-occupation of rearing child and troubled activity related to the family ${ }^{9}$. In $\mathrm{DSH}$, operation is done not usually before 1.5 years of age ${ }^{10}$. Some believe that, though there should be an ideal age range for Hypospadias repair in children, but it is impracticable in our country as the patients come late. However, if any patient is presented at neonatal age they prefer to advise the parents to come for surgery after 1 years of age ${ }^{11}$.

In our patients for group A (study group) Tunica vaginalis Blanket wrap (TVBW) was used in urethroplasty while urethroplasty for group $B$ (control group) was carried out without TVBW. In group A (study group) the operative procedure was Snodgrass urethroplasty in $70 \%$ patients and Kings Duplay type tube urethroplasty in $30 \%$ pts. In group B (control group) the operation procedure was Snodgrass ${ }^{12}$ method in $80 \%$ of patients and KingsDuplay type tube in $20 \%$ patients.

Post urethroplasty follow up, in this series, shows that postoperative fever occurred in 1 patient $(10 \%)$ in control group B which remained up to 4 days. Postoperative periurethral infection developed in 1 patient $(10 \%)$ in group $B$. urethrocutaneous fistula was present in 1 patient (10\%) in group A post operatively (where the skin was found inflamed, oedematous with sloughting at distal part of wound) and in 5 patients (50\%) in group B postoperatively and subsequently 2 more patients developed fistula during follow up period. 1 patient developed fistula due to meatal Stenosis who did not comply with regular meatal dilatation. 
In study group (group A urethroplasty with the application of tunica vaginalis wrap as a second layer)

- In group A metal Stenosis developed in 4 patients in $1^{\text {st }}$ follow up, which responded to dilatation in 2 patients in $2^{\text {nd }}$ follow up and till the end of $3^{\text {rd }}$ follow up 1 patient was continuing regular meatal dilatation. In the original study total 10 patients developed meatal Stenosis out of $31(32 \%)^{6}$.

- In study group A urethral stricture developed in 1 patient $(10 \%)$ in $2^{\text {nd }}$ follow up which was treated with regular urethral dilatation under general anesthesia. In the original study only 1 patient develop urethral stricture out of $31(3 \%)^{6}$. In control group (group B urethroplasty without the application of tunica vaginalis as a second layer over the neourethra.)

- 7 patient $(70 \%)$ developed urethrocutaneous fistula out of 10 patients $(n=10)$ despite of using periurethral flap of tissue as second layer over the neourethra. The suture overlapped the $1^{\text {st }}$ suture of neourethra which might be a cause of development of fistula.

In the original study by Snow et al ${ }^{4}$ the fistula rate of $9 \%$ using a tunica vaginalis blanket wrap confirms the success of this approach.

There is no specific established data of development of urethrocutaneous fistula after urethroplasty in our country. But in one study $(\mathrm{BICH})$ urethrocutaneous fistula topped the list of various complications $(34.38 \%)^{13}$. In another study of BSMMU, the rate of urethrocutaneous fistula is $33.33 \%{ }^{14}$. In another study of $\mathrm{BICH}$, the urethrocutaneous fistula rate is $13.33 \%{ }^{15}$.

In our study, the rate of development of urethrocutaneous fistula is much less (only 10\%) in study group.

By comparing the surgical outcome of urethroplasty by applying tunica vaginalis blanket wrap as a second layer over the neourethra the fistula rate in group $A$ (study group) is much less in comparison to group $B$ (control group) where TVBW was not applied. So the result is significant as evidenced by $P$ value which is less than $<0.01$.

This study demonstrates that use of tunica vaginalis as a blanket wrap as second layer over the neourethra reduces the rate of development of urethrocutaneous fistula.

\section{Conclusion:}

The duration of operating time will be decreasing with more frequent operations and by the surgeons with more experience. The present study shows the lower rate of urethrocutaneous fistula formation. Thus, it can be recommended for hypospadias repair whenever the question of posturethroplasty fistula comes in the list of complications.

\section{References:}

1. Murphy, J.P.,'Hypospadias', in Ashcraft, K.W., Murphy, J.P., Sharp, R. J., (eds), Pediatric surgery, $3^{\text {rd }}$ edn., W. B. Saunders, Philadelphia, Pennsylvania, 2000; pp.763-782.

2. Sweet, R. A., Schrott, H.G., Kurland, R.,Culp, O.S., 'Study of the incidence of hypospadias in Rochester, Minnesota 1940-1970, and a case control comparisn of possible etiologic factors', Mayo clin. Proc., 49: pp 52-8.

3. Mouriquand, P.D.E., Mure, P.Y.'Hypospadias' in Gearhart, J.P., Rink, R.C., Mouriquand, P.D.E., (eds), Pediatric urology, W. B. Saunders, Philadelphia, Pennsylvania, 2001; pp.713-727

4. Snow, B.W., Cartwright, P.C., Unger, K., 'Tunica vaginalis blanket wrap to prevent urethrocutaneous fistula: An 8 year experience', J. Urol., 1995; 153: pp. 472-473.

5. Shapiro, S.R., 'Fistula repair' in Ehrlich, R.M., Alter, J.M., (eds), Reconstructive and Plastic Surgery of the external genitalia: Adult and pediatric, W. B. Saunders, Philadelphia, Pennsylvania, 1999; pp.132-136.

6. Snow, B.W., Cartwright, P.C., 'Tunica vaginalis blanket wrap' in Ehrlich, R.M., Alter, J.M., (eds), Reconstructive and Plastic Surgery of the external genitalia: Adult and pediatric, W. B. Saunders, Philadelphia, Pennsylvania, 1999; pp.109-112.

7. Zaontz, M.R., 'Thiersch-Duplay procedure' Ehrlich, R.M., Alter, J.M., (eds), Reconstructive and Plastic Surgery of the external genitalia: Adult and pediatric, W. B. Saunders, Philadelphia, Pennsylvania, 1999; pp.48-53. 
8. Schultz, J.R., Klykylo, W. M., Wacksman, J., 'Timing of elective hypospadias repair in children', Paediatrics, 1983, 71: 3., pp.342-351.

9. Islam M.S., Personal communication, 13 March 2005.

10. Karim M.S., Personal communication, 1 I March 2005.

11. Islam M. K., Personal communication, 13 March 2005.

12. Snodgrass W., 'Tubularized incised plate urethroplasty for distal hypospadias' J. Urol. 151: pp.464-65.
13. Masud, A.K.M.M., 'Hypospadias Surgery: A short outcome', MS thesis, University of Dhaka, Dhaka, 1998.

14. Alam, M.S., 'Comparison of single-stage correction of distal and mid-penile hypospadias by V.T. Joseph's technique and onlay island flap technique' MS thesis, Bangabandhu Sheikh Mujib Medical University, Dhaka, 2000.

15. Khan, M.H.K., 'Comparison between perimeatal based flap (Mathieu) and the tubularised incised plate urethroplasty (Snodgrass) in distal hypospadias.' MS thesis, University of Dhaka, Dhaka, 2003. 